\title{
Implementasi Game Theory Pada Simulasi Dan Perancangan Software Berbasis Matriks Pay-Off Dengan Metode Non-Zero Sum Game
}

\author{
Ghani Mutaqin ${ }^{1, *}$, Fany Parama Admaja ${ }^{2}$, Ainatul Mardhiyah ${ }^{3}$ \\ Jurusan Teknik Informatika, Universitas Islam Negeri Maulana Malik Ibrahim, Indonesia \\ ${ }^{1}$ ghanimutaqin85@gmail.com; ${ }^{2}$ admaja404@gmail.com; ${ }^{3}$ ainadimana@gmail.com; \\ * corresponding author
}

ARTIKEL INFO

Sejarah Artikel

Diterima: 12 Mei 2020

Direvisi: 23 Juni 2021

Diterbitkan: 30 Agustus 2021

Kata Kunci

Game Theory

Matriks

pay-off

Non-Zero Sum

\section{ABSTRAK}

Tujuan dari penilitian ini adalah untuk merancang suatu aplikasi yang berguna untuk perumusan situasi pengambilan keputusan menggunakan game-theory. Game-theory sendiri merupakan suatu metode yang berguna untuk melakukan analisis proses pengambiilan keputusan antara pemain yang saling bersaing satu sama lain. Setiap pemain memiliki suatu tujuan, yaitu untuk memperoleh keuntungan semaksimal mungkin dan kerugian seminimal mungkin. Untuk dapat mencapai tujuannya, setiap pemain harus cerdas dan memiliki suatu strategi. Strategi digunakan oleh setiap pemain sebagai aksi dan reaksi terhadap lawan mainnya. Karena itu, pengambilan keputusan strategi yang tepat bisa mempengaruhi hasil permainan tersebut. Strategi yang digunakan oleh setiap pemain direpresentasikan dengan menggunakan matriks payoff yang mana memiliki nilai pada setiap baris dan kolomnya. Pengambilan keputusan ini didasarkan pada dua kriteria , yaitu minimax dan maximin. Nilai dari matriks pay-off sendiri nantinya akan diinputkan langsung oleh user. Aplikasi tersebut nantinya akan menggenerate inputan lalu melakukan perbandingan sehingga didapatkan nilai minimax dan maximin. Dengan aplikasi ini, pemain dapat lebih mudah dan cepat dalam pemiihan keputusan yang akan diambil. Penelitian ini bisa dibilang sukses karena menghasilkan nilai yang akurat. Akan tetapi, kekurangan dari aplikasi ini yaitu proses perhitungan hanya dapat dilakukan apabila matriks payoff memiliki ordo dengan jumlah kelipatan yang sama.

\section{PENDAHULUAN}

Dalam sebuah bisnis, keuntungan merupakan suatu hal yang sangat krusial. Karena keuntungan memberikan dampak dalam berlangsungnya sebuah industri. Kerugian juga hal yang harus diperhatikan agar bisa ditekan seminimal mungkin [1]. Dalam teori permainan, keuntungan akan dicari sebesar mungkin, sedangkan kerugian akan ditekan dengan sekecilkecilnya [1]. Dalam penerapannya, terdapat dua macam metode pada teori permainan. Yaitu Zero Sum Game dan Non-Zero Sum Game. Teori Zero Sum Game adalah teori dimana keuntungan setara dengan kerugian, sehingga perubahan yang terjadi adalah nol. Teori permainan non-zero sum game dilakukan untuk melihat pada kemungkinan terbaik dan terburuk dari strategi yang digunakan dalam pengambilan keputusan [2].

Strategi yang optimal untuk dipertimbangkan ialah dengan melihat nilai pay-off [3]. Nilai dari matriks pay-off adalah nilai yang diharapkan terjadi dari strategi yang digunakan. 
Dimana hal ini dimaksudkan untuk mendapat keuntungan maksimal dan kerugian minimal dalam permainan [4].

Penelitian yang pernah dilakukan dalam penerapan matriks pay-off adalah pada konsep game theory pada pengambilan keputusan dalam pemilihan kepala daerah Jawa Barat 2013 [5]. Penelitian tersebut menggunakan metode non-zero sum game dengan hasil dari survei pada masa kampanye. Hasil yang ditunjukkan penelitian tersebut ialah game theory, masing-masing pasangan calon disarankan agar melakukan strategi tertentu untuk melakukan penjaringan secara optimal pada suara yang dibutuhkan.

Maka dari itu, penulis mencoba membuat rancangan software dengan mengimplementasikan konsep dari teori permainan dengan metode non-zero sum game pada matriks pay-off.

\section{METODE}

\section{Non-Zero Sum Game}

Metode menggambarkan situasi di mana keuntungan dan kerugian agregat pihak-pihak yang berinteraksi bisa lebih kecil dari atau lebih dari nol. Zero-sum game juga disebut sebagai permainan yang sangat kompetitif, sedangkan permainan yang bukan merupakan zero-sum bisa bersifat kompetitif atau non-kompetitif. Game zero-sum paling sering diselesaikan dengan teorema minimax yang terkait erat dengan dualitas pemrograman linier.

Dalam perancangan software ini, kami merancang dan mengembangan metode nonzero sum game pada matriks pay-off dengan editor Netbeans 8.2 menggunakan bahasa java. Dalam pengembanganya, kami memasukkan variable-variabel yang dibutuhkan agar nilai matriks yang diinginkan sesuai dengan konsep nilai tidak sama dengan nol. Variablevariabel yang kami deklarasikan dalam perancangan software ini antara lain ialah baris, kolom, nilai maksimin, nilai minimax, dan pay-off. Konsep pada perancangan software ini digambarkan pada flowchart pada Gambar 1.

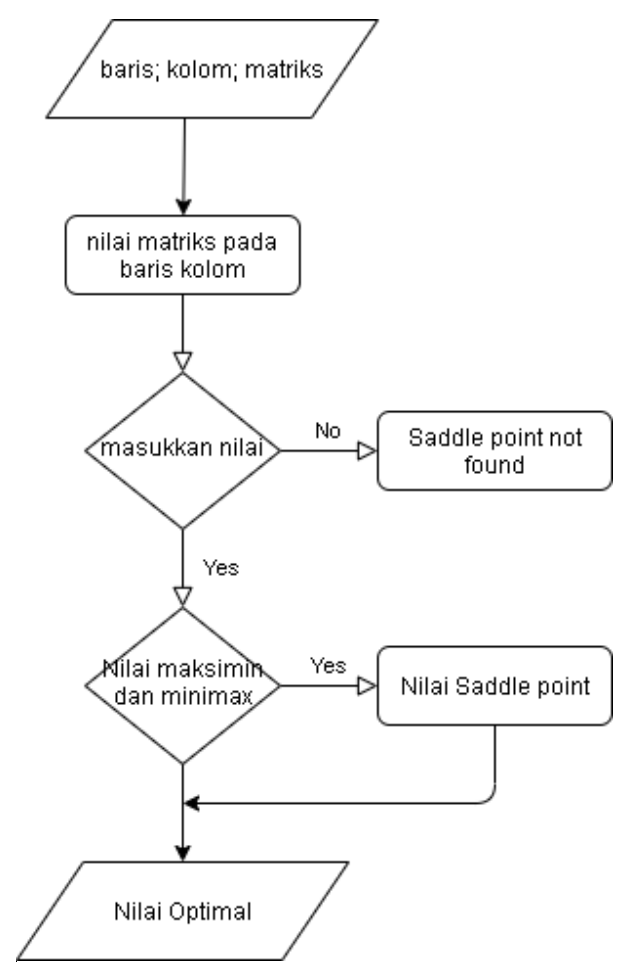

Gambar 1. Proses perancangan software dengan metode non-zero sum game 


\section{Matriks Pay-Off}

Pada konsep Game Theory, dari setiap strategi yang digunakan, setiap pemain akan mendapatkan keuntungan dan kerugian. Keuntungan atau kerugian yang didapatkan bisa ditentukan dengan melihat nilai pay-off dari strategi masing-masing pemain. Pay-off dalam suatu permainan menyatakan ukuran seberapa bagus pemain dalam melakukan suatu permainan[6][7].

Nilai dari pay-off tersebut, terdapat pada matriks yang disebut matriks pay-off. Dalam perancangan software ini, kami menggunakan konsep non-zero sum sehingga didapatkan bentuk umum dari matriks pay-off yang kami gunakan. Betuk umum dari matriks yang digunakan[3] bisa dilihat pada Gambar 2.

$$
\left.\begin{array}{cccc}
A_{1} & C_{1} & \ldots & C_{k} \\
B_{1} & {\left[\left(a_{111}, b_{111}, c_{111}\right)\right.} & \ldots & \left(a_{11 k}, b_{11 k}, c_{11 k}\right) \\
\vdots & \vdots & \ddots & \vdots \\
B_{j} & {\left[a_{1 j 1}, b_{1 j 1}, c_{1 j 1}\right)} & \ldots & \left(a_{1 j k}, b_{1 j k}, c_{1 j k}\right)
\end{array}\right]
$$

Gambar 2. Bentuk Matriks pada metode Non-zero Game

Pada matriks tersebut, interpretasi dari aijk adalah bagi pemain dalam menggunakan nilai pay-off. Sehingga didapatkan rumus yang dapat menentukan nilai pay-off pada sebuah permainan. Rumus tersebut dapat dilihat bisa Gambar 3.

$$
\begin{aligned}
& a_{i j k}=A_{i}-\operatorname{maks}\left(B_{j}, C_{k}\right) \\
& b_{i j k}=B_{j}-\operatorname{maks}\left(A_{i}, C_{k}\right) \\
& c_{i j k}=C_{k}-\operatorname{maks}\left(A_{i}, B_{j}\right)
\end{aligned}
$$

Gambar 3. Rumus untuk menentukan nilai pay-off pada matriks

Pada penerapan Game Theory, menentukan nilai optimal dapat dilakukan dengan metode Ekuilbrium Nash. Ekuilibrium Nash ialah kombinasi dari strategi yang digunakan dengan keadaan dimana satu pemain menggunakan cara yang dilakukan pemain lain sehingga semua pemain menggunakan metode ekuilibrium[8].

\section{HASIL DAN PEMBAHASAN}

\section{Hasil Penghitungan Optimal Pada Matriks Pay-Off}

Dari hasil penelitian dan perancangan yang kami lakukan, kami menyimpulkan bahwa dalam implementasi dari metode non-zero sum game ada beberapa sifat yang harus terpenuhi yaitu :

1. Jumlah pemain terbatas, dimana hal tersebut diwakilkan oleh jumlah baris dan kolom matriks.

2. Kemungkinan yang dimiliki oleh setiap pemain adalah terbatas.

3. Aturan permainan untuk mengukurberbagai kemungkinan dalam permainan.

4. Hasil dari semua kombinasi yang bisa dilakukan adalah bernilai positif atau negative. 
Kami memberikan contoh dengan memasukkan beberapa bilangan sebagai nilai dari matriks tersebut. Contoh dari penerapan tersebut dapat dilihat pada Tabel 1.

Tabel 1. Tabel Matriks dengan ordo 3x3

\begin{tabular}{|c|c|c|c|}
\hline \multirow{2}{*}{ PEMAIN A } & 3 & 5 & 1 \\
\hline \multirow{3}{*}{} & 2 & 1 & 4 \\
\cline { 2 - 4 } & 8 & 6 & 4 \\
\hline
\end{tabular}

Pada tabel matriks tersebut, kami memberikan contoh dengan matriks ber-ordo $3 \times 3$. Menggunakan langkah penyelesaian sebagai berikut:

1. Untuk pemain A, memilih nilai yang paling kecil sehingga akan didapat hasil yang dapat dilihat pada Gambar 4.

$$
\begin{aligned}
& \text { Baris } 1=3 \\
& \text { Baris } 2=1 \\
& \text { Baris } 3=4
\end{aligned}
$$

Gambar 4. Nilai minimal pada setiap baris (pemain A)

Nilai maksimum nya adalah 4 , sehingga 4 merupakan nilai maksimin. Nilai maksimin merupakan nilai keuntungan.

2. Untuk pemain kolom (Pemain B), pilih nilai yang paling besar. Maka didapat hasil yang bisa dilihat pada Gambar 5 .

$$
\begin{aligned}
& \text { Kolom } 1=8 \\
& \text { Kolom 2 }=6 \\
& \text { Kolom } 3=4
\end{aligned}
$$

Gambar 5. Nilai maksimal pada setiap kolom (pemain B)

Nilai minimumnya adalah 4. Jadi minimaksnya adalah 4. Nilai minimaks merupakan nilai kerugian.

3. Karena nilai maksimin sama dengan minimaks, maka terdapat saddle point, yaitu 4. Dengan hasil tersebut, nilai permainan ini dikatakan optimal.

\section{Memodelkan Matriks Pada Source Code Software}

Pada kode program menggunakan bahasa Java yang kami rancang, kami memberikan beberapa method untuk menghitung dan melihat apakah nilai-nilai yang dimasukkan memenuhi syarat atau tidak untuk mendapatkan saddle point, dimana saddle point merupakan nilai optimal. Method-method yang kami gunakan dalam melakukan penghitungan matriks bisa dilihat pada Tabel 2, 3, 4, 5, 6, dan 7 . 
Tabel 2. Method untuk memasukkan nilai matriks

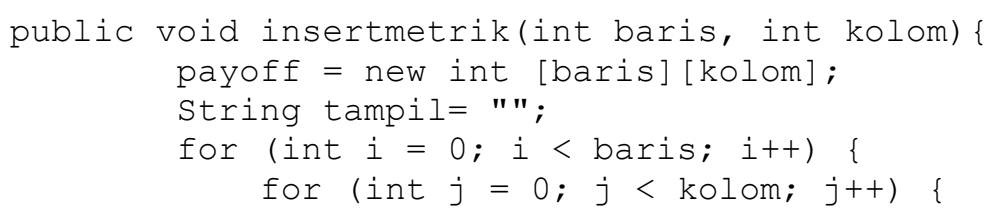

payoff[i][j]=Integer.parseInt (JoptionPane.showInputDialog("Masukkan nilai baris ke "+(i+1)+" kolom ke "+(j+1)+" : "));

Tabel 3. Method untuk menentukan batas jumlah kolom

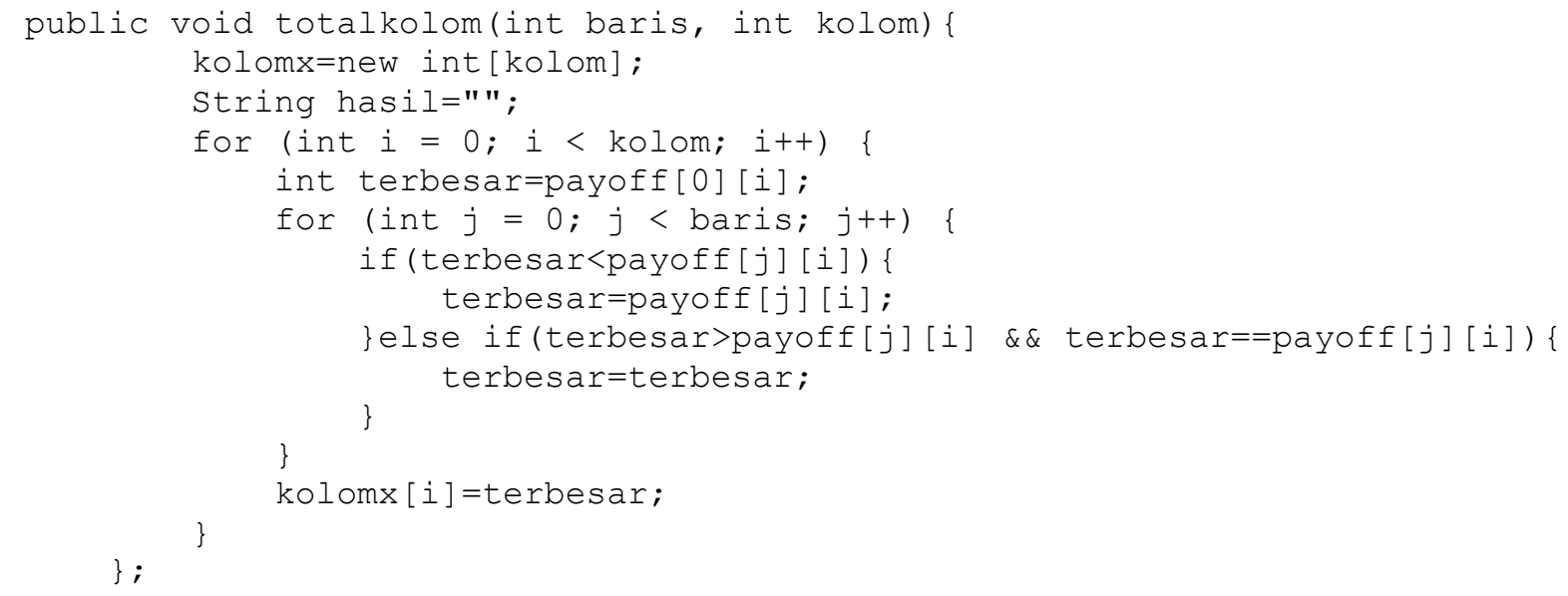

Tabel 4. Method untuk menentukan batas jumlah baris

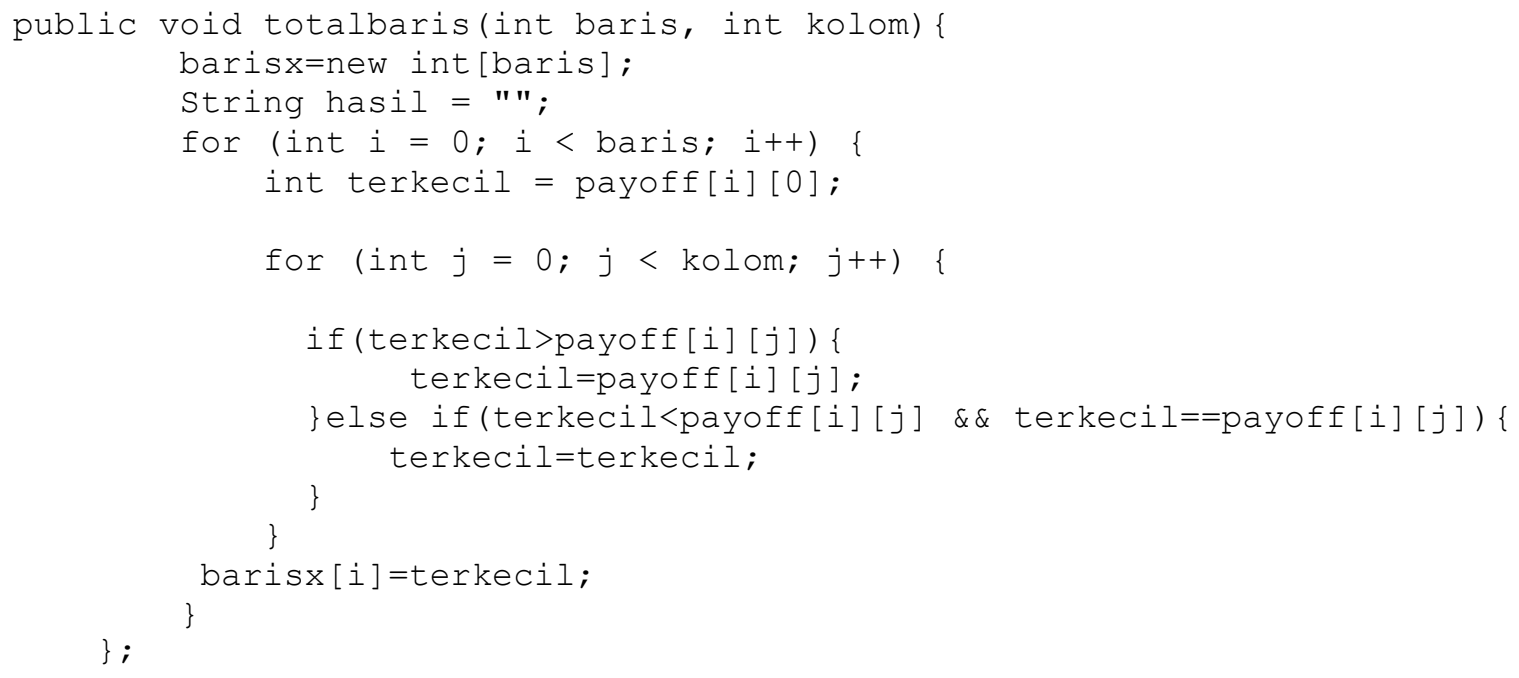


Tabel 5. Method untuk mencari nilai maksimin dan minimaks

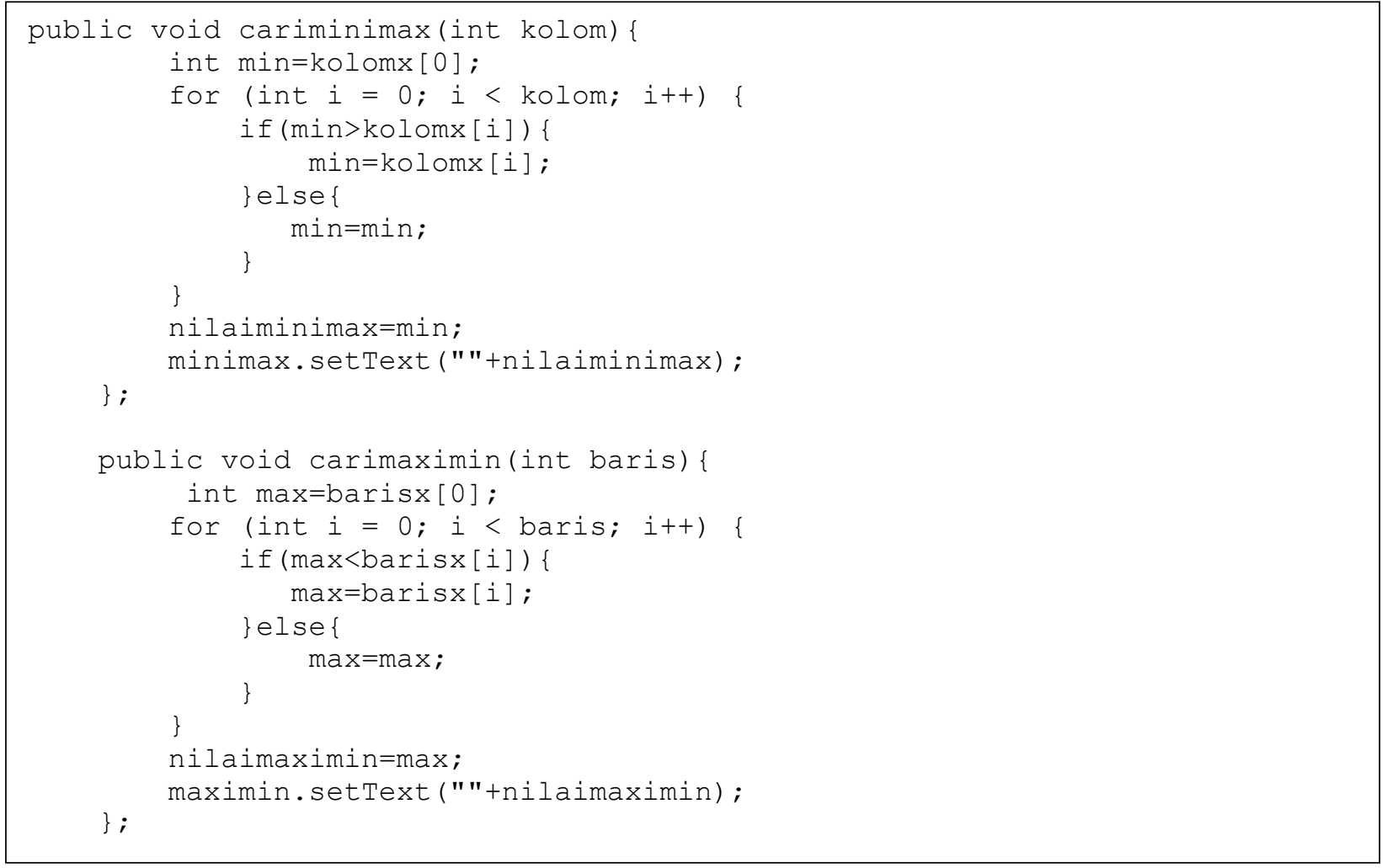

Tabel 6. Method untuk menentukan apakah terdapat saddle-point atau tidak

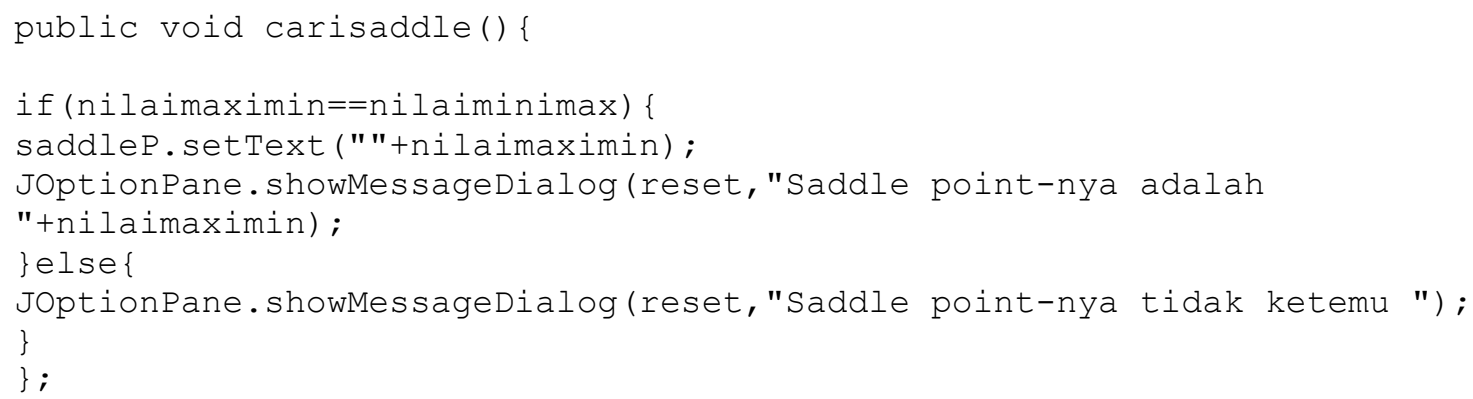

Dari method-method yang telah diberikan tersebut, maka kami menguji coba dengan bilangan yang sama pada matriks yang kami hitung secara manual. Hasilnya adalah bilangan yang keluar pada software ini, sama dengan hasil yang dihitung secara manual. Hasil dari penghitungan menggunakan software yang telah dibuat dapat dilihat pada Gambar 11. 


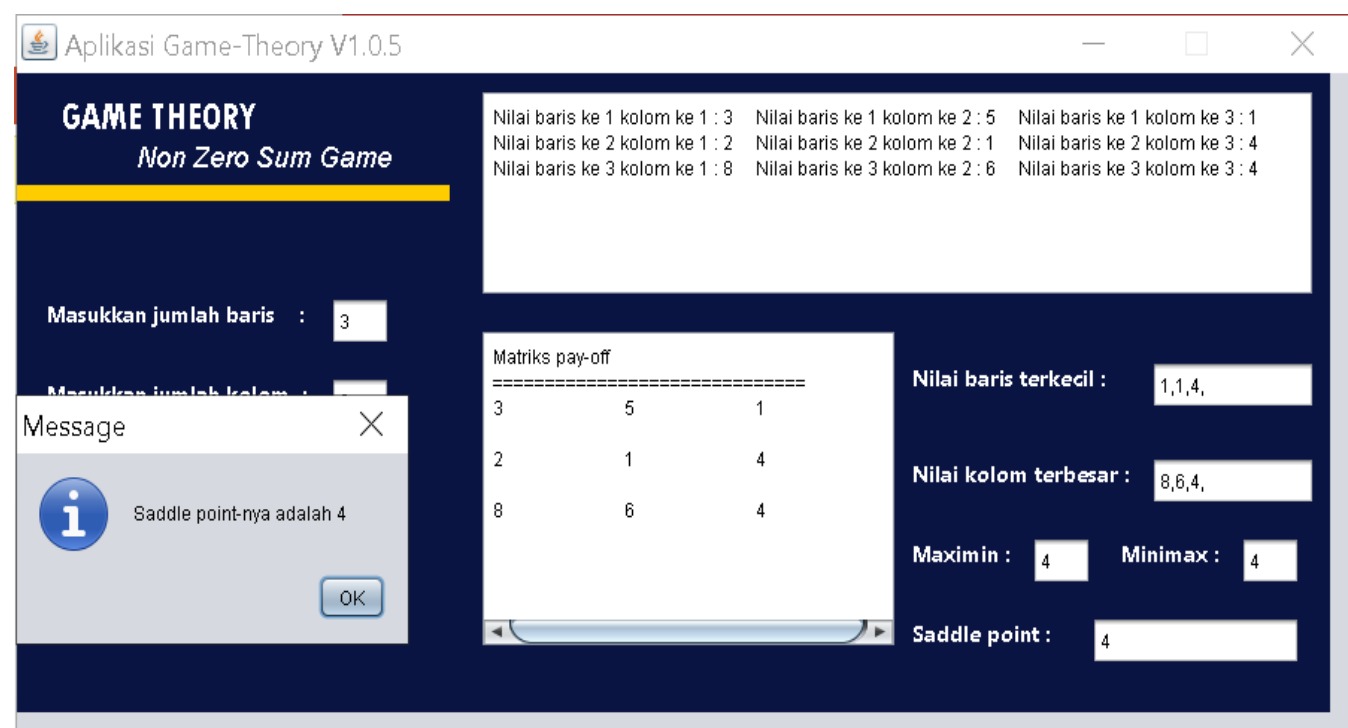

Gambar 6. Hasil penghitungan nilai optimal menggunakan software yang dibuat

\section{KESIMPULAN}

Dari penelitian yang telah dilakukan, dapat disimpulkan bahwa proses pengambilan keputusan menggunakan metode game theory dapat diimplementasikan ke dalam aplikasi dengan menggunakan algoritma matematika. Sehingga proses dalam pengambilan keputusan menjadi lebih cepat dan mendapat hasil akurat. Nilai yang diinputkan oleh user sangat berpengaruh terhadap nilai yang dihasilkan. Apabila nilai minimax dan maximin memiliki nilai yang sama, makan akan didapatkan saddle point. Semakin sedikit jumlah baris dan kolom maka akan semakin cepat proses perhitungannya. Akan tetapi, kekurangan dari aplikasi ini yaitu proses perhitungan hanya dapat dilakukan apabila matriks payoff memiliki ordo dengan jumlah kelipatan yang sama.

\section{REFERENSI}

[1] S. Rathnasiri, P. Ray, S. M. N. Islam, and C. A. Vega-Mejía, "E-commerce Supply Chain Cost Optimization with Incentive Compatibility Constraints," 2019 IEEE Int. Conf. Serv. Oper. Logist. Informatics, pp. 253-257, 2019, doi: 10.1109/SOLI48380.2019.8955039.

[2] X. Li and Q. Zhao, "Study on Cooperation Strategies between Supply Chain Enterprises Based on Evolutionary Game Theory," 2018 15th Int. Conf. Serv. Syst. Serv. Manag. ICSSSM 2018, pp. 1-5, 2018, doi: 10.1109/ICSSSM.2018.8465031.

[3] A. SAIFUDDIN, N. K. T. TASTRAWATI, and K. SARI, "PENERAPAN KONSEP TEORI PERMAINAN (GAME THEORY) DALAM PEMILIHAN STRATEGI KAMPANYE POLITIK (Studi Kasus : Strategi Pemenangan Pemilukada DKI Jakarta Tahun 201," E-Jurnal Mat., vol. 7, no. 2, p. 173, 2018, doi: 10.24843/mtk.2018.v07.i02.p200.

[4] F. Juliyanto and evi yuliawati Sari, “Analisis persaingan perbankan dengan,” vol. 5, no. 1, pp. 54$62,2018$.

[5] K. Mustaqim, "Kiki Mustaqim, 2013 Aplikasi Konsep Teori Permainan Dalam Pengambilan Keputusan Politik Universitas Pendidikan Indonesia | repository.upi.edu,” pp. 17-62, 2013.

[6] M. J. Dema, "a Non-Zero Sum Game : How Game Theory Can Inform Better Transboundary Water Rights Treaty Drafting,” Eur. Sci. J., vol. 2, no. September, pp. 126-142, 2014.

[7] C. T. Leondes and R. K. Nandi, "An application of non-zero-sum games to competitive decision making†,” Int. J. Syst. Sci., vol. 8, no. 9, pp. 1009-1020, 1977, doi: 10.1080/00207727708942098.

[8] "ANALISIS TEORI PERMAINAN DAN EKUILIBRIUM NASH PADA SIMULASI LELANG ( AUCTION ) PASAR LISTRIK HENNY IKA SEPTYANI NIM : 23205047 Program Studi Teknik Tenaga Elektrik INSTITUT TEKNOLOGI BANDUNG ANALISIS TEORI PERMAINAN DAN EKUILIBRIUM NASH PADA SIMULASI LELANG ( AUCTION ) PASAR LISTRIK,” 2007. 